\title{
Biodegradation/Disintegration of Selected Range of Polymers: Impact on the Compost Quality
}

\author{
Dana Adamcová ${ }^{\cdot}$ Jan Zloch $^{1} \cdot$ Martin Brtnický2,3 $\cdot$ Magdalena Daria Vaverková ${ }^{1,4}(\mathbb{C}$
}

Published online: 18 February 2019

(c) The Author(s) 2019

\begin{abstract}
This study provides information about behaviour of selected polymeric materials in laboratory and home composting conditions. Polymeric samples certified as compostable have degraded in laboratory conditions. Selected samples showed low decomposition of material in real composting conditions. Polymeric sample labelled by the producer as " $100 \%$ degradable" did not show any visual signs of degradation in the laboratory conditions as well as in the real conditions. Research was aimed also to the effect of biodegradation/disintegration of polymeric samples on compost quality. Tests of phytotoxicity with Sinapis alba L. and Hordeum vulgare L. were done for every sample of compost but $\mathrm{pH}$ was too low to evaluate the impact of samples to quality of compost. No seeds of the tested plant germinated in $81 \%$ of the started pots. Conclusion of this study is that there is a different outcome between decomposition of biodegradable/disintegrable plastic material in laboratory conditions and real composting conditions. Furthermore, it was found that some polymeric materials advertised by the producer as " $100 \%$ degradable" are stable and do not decompose.
\end{abstract}

Keywords Biodegradation/disintegration $\cdot$ Plastics $\cdot$ Composting $\cdot$ Laboratory condition $\cdot$ Phytotoxicity tests

\section{Introduction}

Synthetic polymers (plastics) are deemed one of the most frequently used materials in everyday life. The production of oil-based plastics keeps growing every year [1]. An enormous amount of plastic waste is still landfilled or left in the environment and have become a serious environmental threat due to their contribution to the ever-increasing amount of solid waste [2]. Worldwide, plastic products and

Magdalena Daria Vaverková

magda.vaverkova@uake.cz

1 Department of Applied and Landscape Ecology, Faculty of AgriSciences, Mendel University in Brno, Zemědělská 1, 61300 Brno, Czech Republic

2 Department of Geology and Pedology, Faculty of Forestry and Wood Technology, Mendel University in Brno, Zemědělská 1, 61300 Brno, Czech Republic

3 Central European Institute of Technology, Brno University of Technology, Purkyňova 656/123, 61200 Brno, Czech Republic

4 Department of Environmental Improvement, Faculty of Civil and Environmental, Engineering, Warsaw University of Life Sciences - SGGW, Nowoursynowska 159, 02776 Warsaw, Poland their components appear freely along road sides, in parks, at beaches, in the oceans and so on $[3,4]$.

The level of oil source reliance could be reduced by the advance of bioplastics, using biological sources or more specifically annually with renewable resources [5]. Biodegradable plastics appear to be a way of reducing the negative influence of plastic waste on the environment. A line of plastic materials that are degraded by microorganisms under certain environmental conditions (humidity, temperature and UV light) has been invented [6]. Now a day's biodegradable materials are of prime interest for environmental reasons [7]. What is more, due to biological degradability, the production of bioplastics has received considerable attention. Therefore, study of the biodegradability plays a significant role in development of biopolymers [8]. The objective is to set up a sustainable environment and restrict potential deposits of inappropriate plastic waste in the environment. The term bioplastics can basically be linked to biologically-based plastics synthesised from biomass and renewable resources such as polylactic acid (PLA) and polyhydroxyalkanoate (PHA) or plastics made from fossil fuels including aliphatic plastics such as polybutylene succinate (PBS) which can be utilised as a substrate for microorganisms [9]. The most studied biodegradable polymers are polysaccharides (cellulose derivatives, primarily starch) 
or aliphatic and mixed aliphatic/aromatic polyesters [10]. Using biodegradable plastics has many restrictions such as for instance the high price, as well as moisture sensitivity, narrow processing windows, low heat deflection temperatures, and/or poor barrier and conductivity properties [5]. To assess the relative impact of each type of polymer on the environment it is essential to carry out evaluation of the product's life circle (i.e. from cradle to grave), which makes manufacture more expensive [10]. Although consumers have a limited knowledge of their origins, usability for products and overall environmental performance, they recognise the positive value of using bioplastics [11]. Though many various definitions of bioplastics exist they are perceived as plastic materials where the carbon originated from renewable resources (maize starch or cellulose for instance) [11-13]. Compared to oil-based plastics (which are resistant against microbial attack) bioplastics are theoretically compostable in a short space of time. Bioplastics use might be one of the techniques that would settle the massive issue of plastic waste, but since these new materials are proposed to be disposed directly on the environment the eventual risks associated to polymers and its by-products should be assessed [14]. Bioplastics production tends to consume less power and does not generate toxic side products. For this reason, bioplastic products are deemed to be "environmentally friendly" $[12,15]$. However, the current procedures and processes for handling waste are not best suited to managing bioplastics $[16,17]$. It is vital to monitor the impact of these biodegradable/disintegrable polymeric materials on the environment and the management of waste. This will bring actual benefits while making it possible to establish corresponding systems and legislation for waste management [18].

Critical review of norms and standards and corresponding tests to determine the biodegradability of biodegradable plastics has been in detail presented by Briassoulis and Dejean [19]. Authors also clarify the terminology because the terms "biodegradable", "biopolymer" and "bioplastic" are currently widely used but with some confusion $[19,20]$.

In this study the authors hypothesize that selected polymers behave different in laboratory (controlled conditions) and real composting conditions. In this study we examine different polymeric materials and their biodegradation/ disintegration under laboratory and real conditions (home composting bins). In addition, the influence of the resultant compost after the decomposition process was checked in the terms of its phytotoxic effect on selected plants.

\section{Experimental Procedures}

\section{Research Materials}

The selected polymers (biodegradable/disintegrable) materials were obtained from chain stores in the Czech Republic.
Four kinds of plastic bags were used in this study and cellulose filter paper as a positive control. One of them was a plastic bag made of HDPE and mixed with totally degradable plastic additive (TDPA additive)-labelled by the producer as " $100 \%$ biodegradable" and three were certified compostable (Table 1). Labelling and characterisation of samples is given in Table 1.

\section{Biodegradation/Disintegration Test in Laboratory Conditions}

The degree of disintegration of the pieces obtained was evaluated following a modified version of the ČSN EN 14806 Norm "Packaging - Preliminary evaluation of the disintegration of packaging materials under simulated composting conditions in a laboratory scale test" and a modified version of ČSN EN ISO 20200 "Plastics - Determination of the degree of disintegration of plastic materials under simulated composting conditions in a laboratory-scale test" (ISO 20200:2004). According to these tests, the samples were mixed with a solid biodegradable synthetic material and subjected to aerobic degradation [21] (Fig. 1). The experiment was carried out for a period of 12 weeks at a controlled temperature of $58^{\circ} \mathrm{C}$ (Ecocell chamber). During the test, the contents of the vessel were regularly manually mixed and aerated. When mixing and aerating, the visual appearance of the test items was carefully checked.

The amounts of synthetic waste and samples placed in each reactor are listed in Table 2.

The composition of the synthetic biodegradable material was changed as follows (as a percentage of dry mass): $3 \%$ compost, $16 \%$ wood sawdust, $64 \%$ biodegradable municipal waste and $2 \%$ glucose (the other composition of the synthetic material-Table 3). This modification was undertaken in order to bring the test nearer to real conditions and is based on research on the monthly production of biodegradable waste in twenty families. For each tested material two reactors were prepared.

The laboratory experiment lasted 12 weeks. Once the experiments were over, the samples under scrutiny were sieved through a $2 \mathrm{~mm}$ sieve and the material that remained in the sieve was deemed non-degradable. The residue on the sieve

Table 1 Characteristics of samples

\begin{tabular}{lll}
\hline Sample & Material & Designation \\
\hline A/AA & HD-PE & Labelled as "100\% Biodegradable" \\
B/BB & Mater-Bi & OK Kompost AIB VINCOTTE \\
C/CC & Natural material & Compostable 7P0073 \\
D/DD & Mater-Bi & $\begin{array}{c}\text { Compostable 7P0180, OK Com- } \\
\text { post S81 VINCOTTE }\end{array}$ \\
Blank (E) & $100 \%$ cellulose & - \\
\hline
\end{tabular}




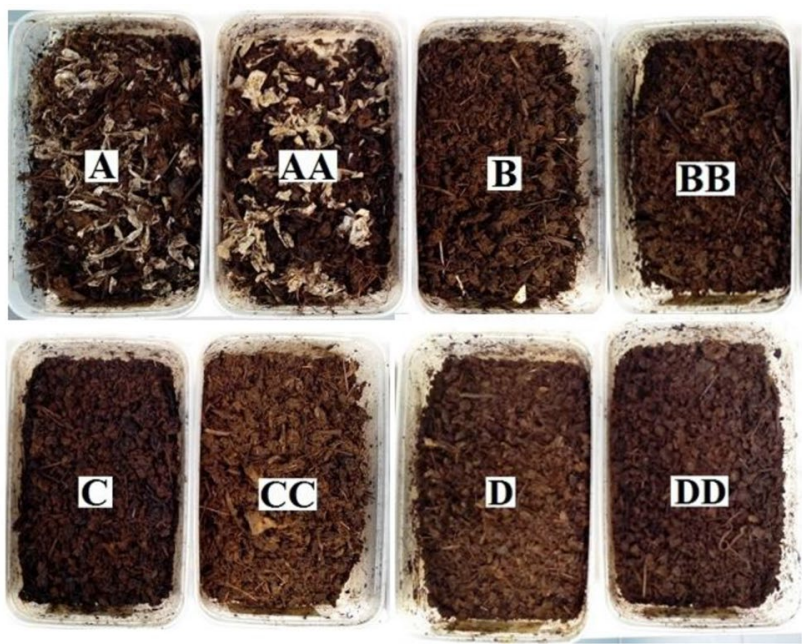

Fig. 1 Set up of the test in laboratory conditions-reactors witch samples

Table 2 The amounts of synthetic waste and samples

\begin{tabular}{llll}
\hline Sample & $\begin{array}{l}\text { Weight of synthetic } \\
\text { waste }(\mathrm{g})\end{array}$ & $\begin{array}{l}\text { Weight of } \\
\text { sample }(\mathrm{g})\end{array}$ & Total weight $(\mathrm{g})$ \\
\hline A & 1168.02 & 5.13 & 1173.15 \\
AA & 1236.43 & 5.69 & 1242.12 \\
B & 1190.98 & 11.21 & 1202.19 \\
BB & 1176.59 & 11.22 & 1187.81 \\
C & 1189.78 & 12.25 & 1202.03 \\
CC & 1191.25 & 12.65 & 1203.90 \\
D & 1184.31 & 10.31 & 1194.62 \\
DD & 1198.73 & 10.42 & 1209.15 \\
\hline
\end{tabular}

Table 3 The composition of the synthetic biodegradable material

\begin{tabular}{lcc}
\hline Material & Weight $(\mathrm{g})$ & Weight $(\%)$ \\
\hline Biodegradable waste & 5960 & 64 \\
Wood sawdust & 1500 & 16 \\
Sunflower oil & 1000 & 11 \\
Starch & 300 & 3 \\
Compost & 300 & 3 \\
Glucose & 180 & 2 \\
Urea & 60 & 1 \\
Total & 9300 & 100 \\
\hline
\end{tabular}

was weighed and the values recorded. The degree of disintegration was subsequently calculated (D) (1):

$\mathrm{D}=\frac{\mathrm{Mi}-\mathrm{Mr}}{\mathrm{Mi}} \times 100(\%)$
Table 4 Designation/ biodegradation of compost samples

\begin{tabular}{ll}
\hline Sample & Compost sample \\
\hline A & A 1 \\
AA & AA 2 \\
B & B 3 \\
BB & BB 4 \\
C & C 5 \\
CC & CC 6 \\
D & D 7 \\
DD & DD 8 \\
\hline
\end{tabular}

D—degree of disintegration (\%), Mi-sample weight at the beginning of the experiment $(\mathrm{g}), \mathrm{Mr}$ - sample weight at the end of the experiment $(\mathrm{g})$.

Apart from biodegradation/disintegration, the laboratory experiment also explored the effect of the biodegradation/ disintegration of samples on compost quality [22]. The compost quality/toxicity was assessed in the pot experiment following procedures adapted from those described in CSN EN 13 432. The method of labelling compost that resulted from the laboratory experiment is outlined in Table 4.

\section{Phytotoxicity Test-Pot Experiment Layout and Plant Material}

The experiment was conducted under laboratory conditions. The phytotoxicity of compost samples was investigated by means of a set of biological tests (Fig. 2). Seed crops (Sinapis alba L. and Hordeum vulgare L.) were purchased locally from the Agriculture Research, Ltd., (Troubsko, Czech Republic). White mustard, (Sinapis alba L.) is annual herbaceous plant of the family Brassicaceae. White mustard is an erect sparsely branching plant with alternate irregularly lobed leaves. The globular light-yellow seeds are finely pitted and odourless when whole and are about $2.5 \mathrm{~mm}$ in diameter. The plants grow rapidly and enter a phase of dense flowering in early summer, reaching their full height of 1.5 to 2 metres as their flowers fade and the fruits appear. Sinapis alba L. is sensitive to chemicals so it is suitable for toxicity tests [23] and is ideal for studying soil/ compost and soil/compost extracts [24, 25].

Barley, (Hordeum vulgare L.), cereal plant of the grass family Poaceae. Hordeum vulgare L., is an annual grass featuring erect stems with few, alternate leaves. Barley is adaptable to a greater range of climate than any other cereal, with varieties suited to temperate, subarctic, or subtropical areas. Hordeum vulgare $\mathrm{L}$. is now widely used for the bioassay experiments [26].

Crops were selected according to their toxicity tolerance: white mustard (Sinapis alba L. - SIA). and barley (Hordeum vulgare L. - HV). Selected seeds were the indicators for the phytotoxicity test, following procedures 
Fig. 2 Experiment principlesset of biological tests
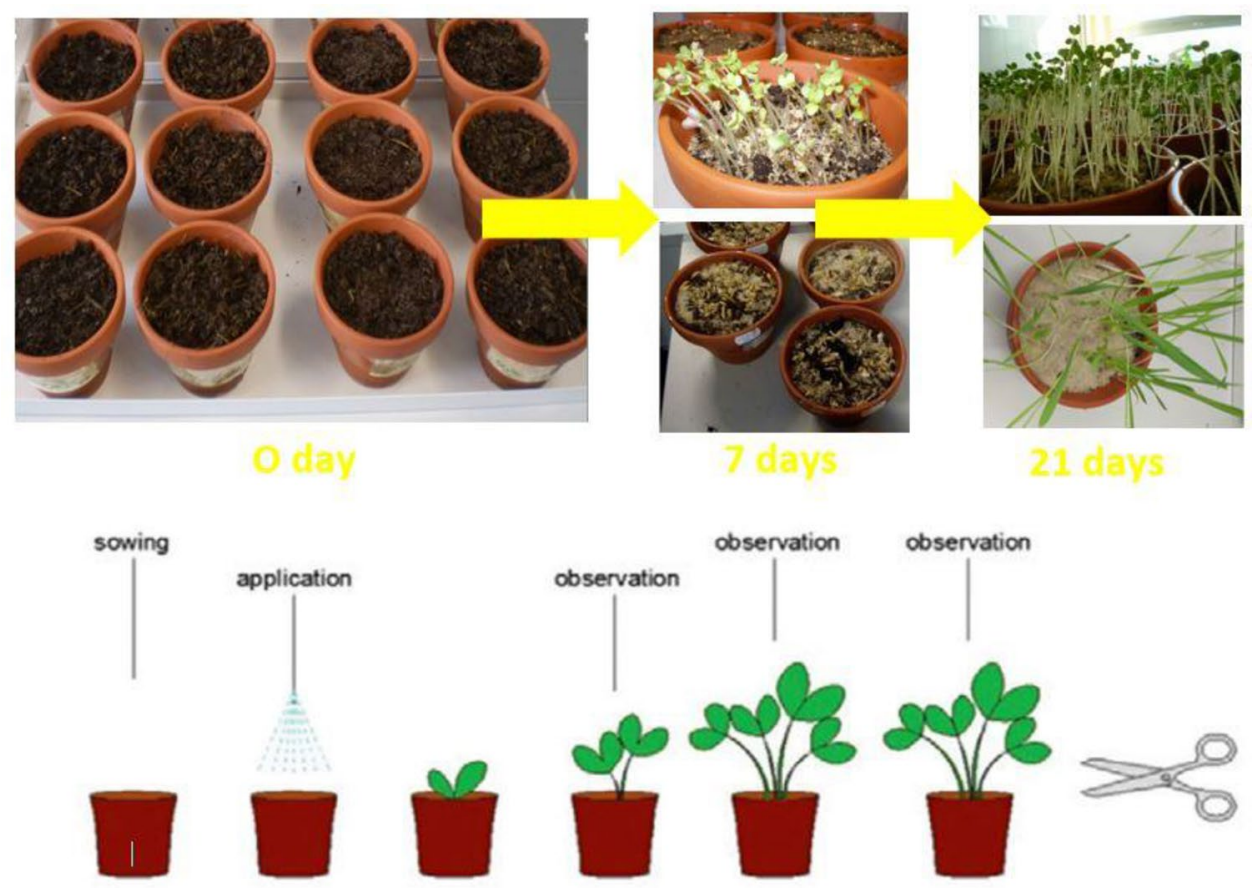

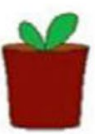

0

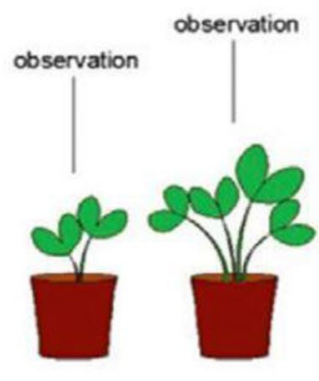

7

14

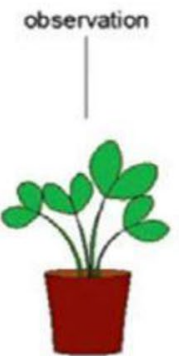

21

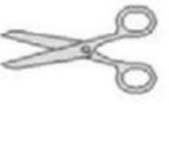

days adapted from those described in CSN EN 13432 [27]. The reference compost was a reference substrate (topsoil, peat and sand).

The medium was commercial potting soil for germination and plant growth and silica sand (8:2), enriched with compost samples ( $25 \%$ and $50 \%)$. The medium was sieved with a $2 \mathrm{~mm}$ standard sieve after air-drying and was stored in a dryer. Seeds were surface-sterilised by soaking in a commercial sodium hypochlorite $(2 \%)$ solution with a few drops of Tween-20 for $2 \mathrm{~min}$. Then they were rinsed twice in sterile distilled water. Each earthen pot with a diameter of $11 \mathrm{~cm}$ and a height of $10 \mathrm{~cm}$ was loosely filled with $100 \mathrm{~g}$ of medium, then 100 seeds of Sinapis alba L and Hordeum vulgare L. were scattered on to the surface, covered with a thin layer of silica sand and the earthen pots were covered with a glass plate (to avoid evaporation). Glass plates were removed when the germinated plants touched them. Plants were grown under controlled conditions for 21 days. Humidity was at a level of $70-100 \%$ of water absorption capacity, there was low light intensity and the laboratory temperature was maintained as constant. The experimental design was based on the use of two replicates per treatment. Values obtained from two simultaneously conducted experiments were averaged and presented. During the experiment, evaporated water was regularly added as needed. The $\mathrm{pH}$ was measured in all the pots.

\section{Biodegradation/Disintegration Test in Home Composting Environment}

The research was aimed at verifying the degradation of research plastic materials under home composting conditions. The objective of the research was to find out how those plastics behave in conditions other than laboratory or real composting conditions (controlled conditions). The experiment took place in home wooden compost bins (Fig. 3). The bins were placed in an apple orchard under a southern slope at a distance of about $10 \mathrm{~m}$ from a brick wall of a building. Direct sunlight was falling on the compost bins throughout the whole morning and after 2 pm the bins were placed into shade. The experiment lasted for 12 months.

\section{Results and Discussion}

\section{Laboratory Conditions}

The experiment in laboratory conditions was terminated after 12 weeks. Samples were visually assessed and documented in photographs. Using visual assessment, the B, BB, C, CC and D, DD samples disintegrated completely. Conversely, the A, AA samples failed to disintegrate (Fig. 4).

Synthetic waste parameter: $\mathrm{pH}$ and temperature were monitored daily in the course of the experiment (Fig. 5). 
Fig. 3 Home wooden compost bin

Fig. 4 Photographs of samples once the composting under laboratory conditions ended
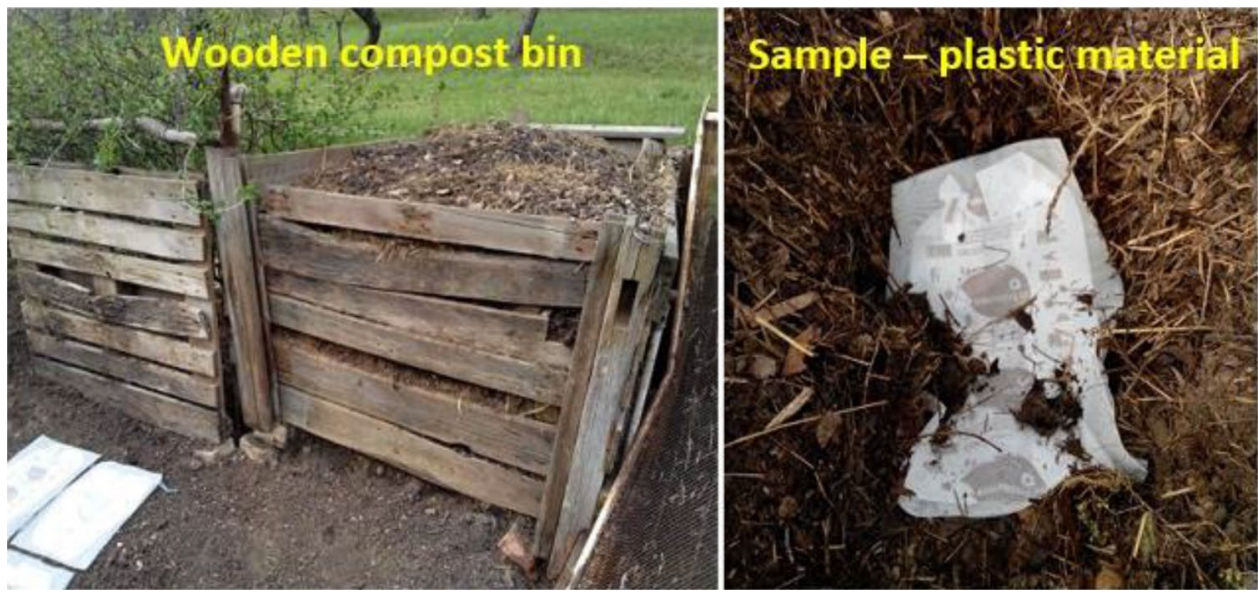
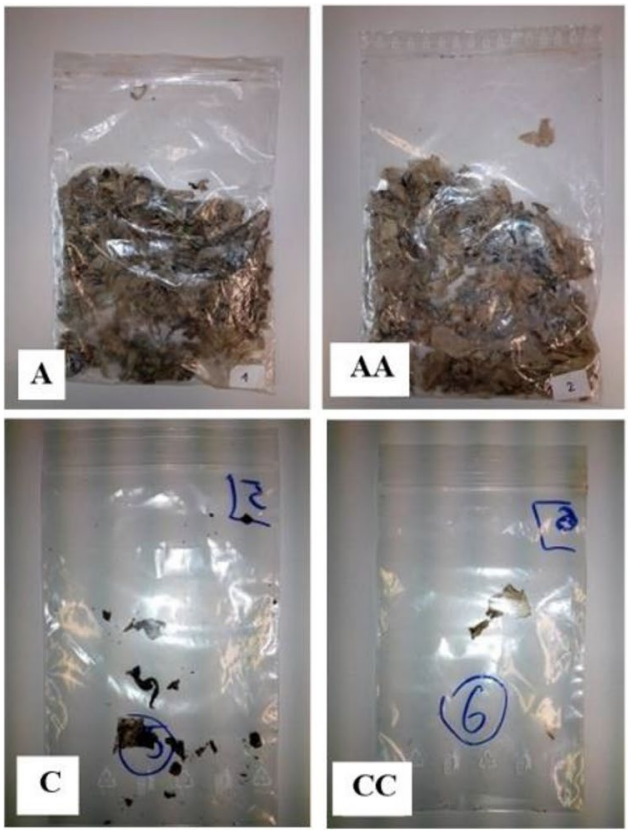
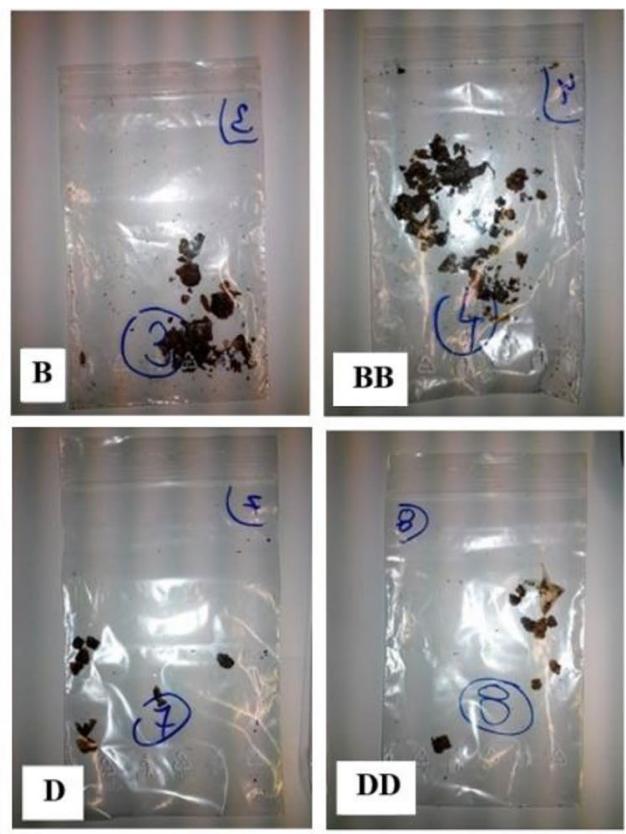

The temperature of synthetic waste attained $55.5^{\circ} \mathrm{C}$ on average while the average $\mathrm{pH}$ value was 3.5 . The $\mathrm{pH}$ values were very low due to the unsuitable composition of the synthetic waste in accordance with the CSN EN 14806 standard. The authors are of the opinion that the synthetic waste composition should have been modified to attain the best possible conditions for composting. Once the experiment was complete, the remaining samples were weighed, and the degree of disintegration was calculated using the Eq. (1). The results obtained are stated in Table 5.

In case of the A and AA sample, we recorded a negative figure of the disintegration degree (average value of $-6.5 \%$ ), caused by the compost residue sticking to the underrated components of the sample. These impurities could not be removed without damaging the remaining parts of the samples. The $\mathrm{C}$ and $\mathrm{CC}$ sample demonstrated the highest degree of disintegration, $99.4 \%$ on average. Other samples also manifested a high degree of disintegration. The average value of the disintegration in case of the B and BB samples was $93.5 \%$ and $98.7 \%$ in case of the D and DD samples.

To determine the compost quality, phytotoxicity tests were carried out using composts resulting from the disintegration of the materials tested under laboratory conditions. Of all the started pots, the tested plant of Sinapis alba L. and Hordeum vulgare L. germinated in 9 containers. No seeds of Sinapis alba $\mathrm{L}$. germinated in any of the remaining pots. The results were stated in Table 6 .

Low germination values were found in the phytotoxicity test. No seeds of the tested plants germinated in $81 \%$ of the started pots and the germination values are low in the remaining pots (10.3-23.7\%). This is due to the low $\mathrm{pH}$ of the tested composts. 


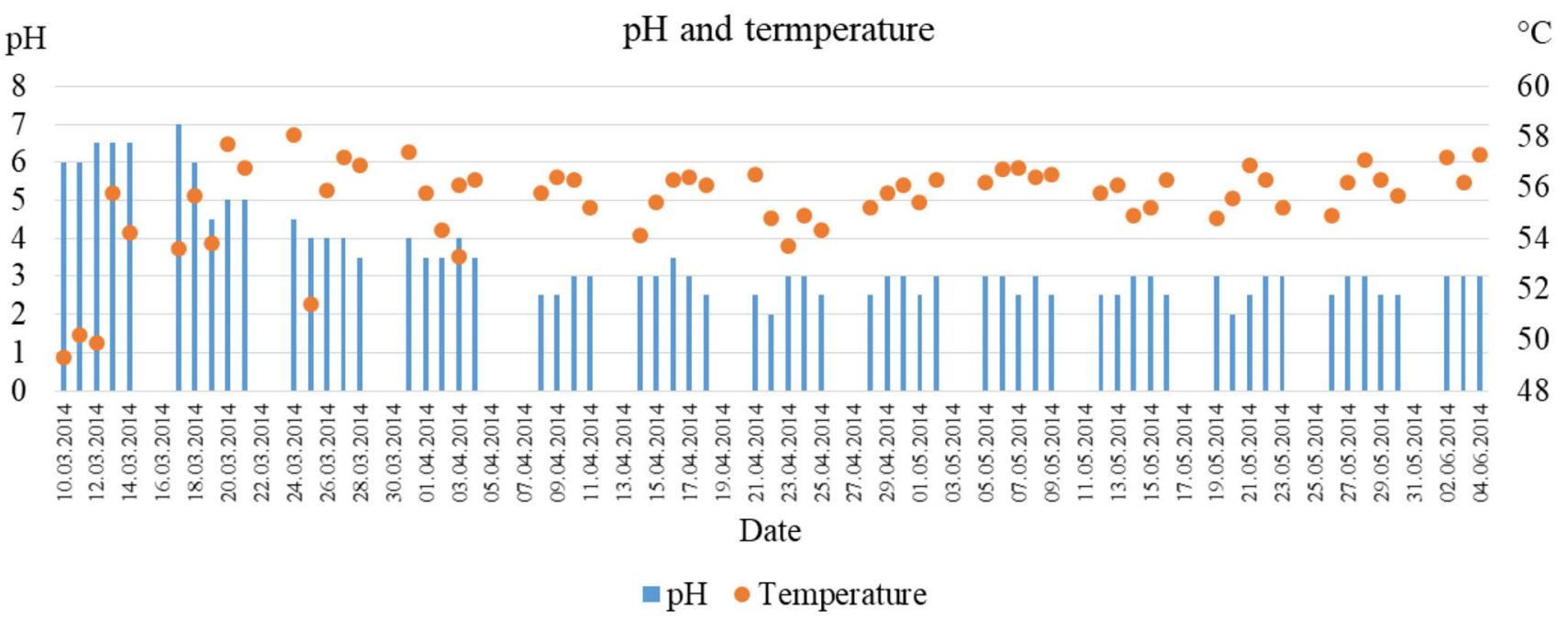

Fig. 5 The course of $\mathrm{pH}$ and temperature in the case of the composting under laboratory conditions experiment

Table 5 Results of the degree of disintegration in laboratory composting conditions

\begin{tabular}{|c|c|c|c|c|c|c|c|c|}
\hline Sample & A & AA & B & BB & C & $\mathrm{CC}$ & D & DD \\
\hline $\begin{array}{l}\text { Degree of disin- } \\
\text { tegration }(\%)\end{array}$ & -9.0 & -4.0 & 93.9 & 93.0 & 98.9 & 99.8 & 98.8 & 98.6 \\
\hline $\begin{array}{l}\text { Mean-degree of } \\
\text { disintegration } \\
(\%)\end{array}$ & -6.5 & & 93.5 & & 99.4 & & 98.7 & \\
\hline
\end{tabular}

Table 6 Phytotoxicity test results in compost samples

\begin{tabular}{lllll}
\hline Sample & Vessel designation & $\begin{array}{l}\text { Mean-Number of } \\
\text { germinated seeds }\end{array}$ & $\mathrm{pH}$ & Germination (\%) \\
\hline A (SIA) & A1 25b & 8 & 3 & 10.5 \\
B (SIA) & B3 25a, B3 25b & 18 & 3 & 23.7 \\
A (HV) & A1 25b & 8 & 3 & 10.3 \\
B (HV) & B3 25a, B3 25b & 16 & 3 & 20.5 \\
Blank (E) (SIA) & Ea, Eb, Ec & 76 & 3.5 & - \\
Blank (E) (HV) & Ea, Eb, Ec & 78 & 3 & - \\
\hline
\end{tabular}

Identical samples were tested for 12 months in home composting conditions. $\mathrm{pH}$ and temperature were monitored weekly in the course of the experiment (Fig. 6). The temperature of the composting pile reached $36.9^{\circ} \mathrm{C}$ on average while the average $\mathrm{pH}$ value was 6.8 .

The composition of the blanc samples confirmed the suitable composting conditions. Having completed the test, the leftover material was photographically documented and visually reviewed, weighed and the degree of disintegration was calculated using Eq. (1). Sample weights before and after test completion and the figures for degree of disintegration can be found in Table 7. For photographs of samples after the experimental period see Fig. 7.

Disintegration was recorded only in the case of the B and D samples. Other samples (A and C) were not subject to disintegration and their weight rose due to the remnants of compost stuck to the parts of samples that had not disintegrated. The degree of sample disintegration after experiment completion over 12 months was as follows. The disintegration degree of sample A was-51.4\%, B 14.1\%, C-5.0\% and D $6.7 \%$. 


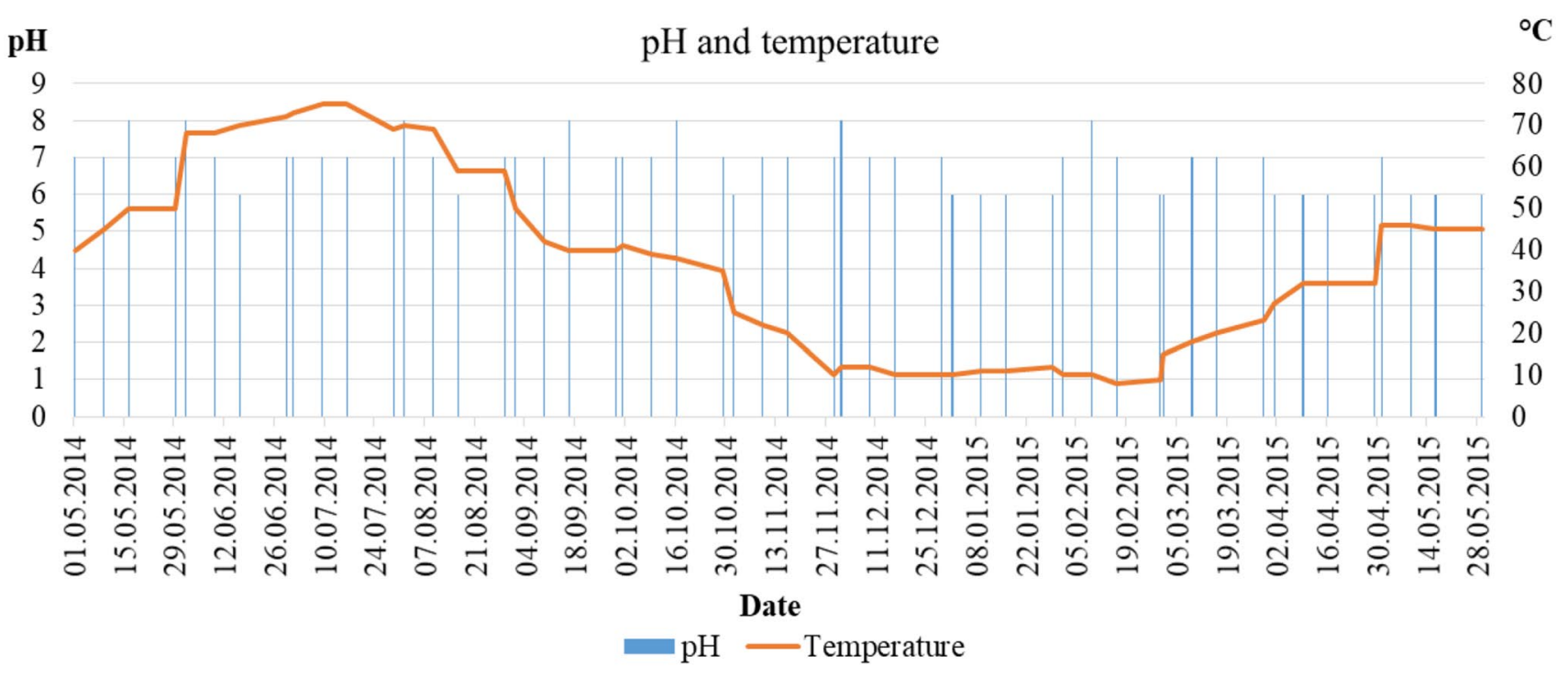

Fig. 6 The course of $\mathrm{pH}$ and temperature in the case of the composting under real conditions experiment

Table 7 Disintegration degree results in domestic composting conditions

\begin{tabular}{|c|c|c|c|c|}
\hline Sample & A & B & C & D \\
\hline $\begin{array}{l}\text { Weight-the beginning of the experi- } \\
\text { ment }(\mathrm{g})\end{array}$ & 5.16 & 11.26 & 12.78 & 10.39 \\
\hline Weight-the end of the experiment (g) & 7.81 & 9.67 & 13.42 & 9.69 \\
\hline Degree of disintegration $(\%)$ & -51.4 & 14.1 & -5.0 & 6.7 \\
\hline
\end{tabular}

\section{Conclusion}

The research suggests that the samples under scrutiny manifest higher degree of disintegration in laboratory conditions; i. e. $97.2 \%$ on average in the case of samples $\mathrm{B}, \mathrm{C}$ and $\mathrm{D}$, while sample A only attained a $-6.5 \%$ degree of disintegration. Test results obtained under real composting conditions came to a different outcome. After the duration of 12 months only samples B and D exhibited any signs of disintegration - the disintegration degree in case of sample B came to $14.1 \%$ and $6.7 \%$ in the case of the D sample. Samples A and C showed no sign of disintegration on visual review and failed to manifest any signs of disintegration when calculating the grade of disintegration. The disintegration level of sample A was $-51.4 \%$ and $-5.0 \%$ in case of sample C. The experiment carried out suggests that materials should also be tested in real conditions that differ from those in a laboratory, as these samples are intended for clients who can compost them in actual conditions. This study opens new doors for materials manufacturers who should focus on testing under real conditions.
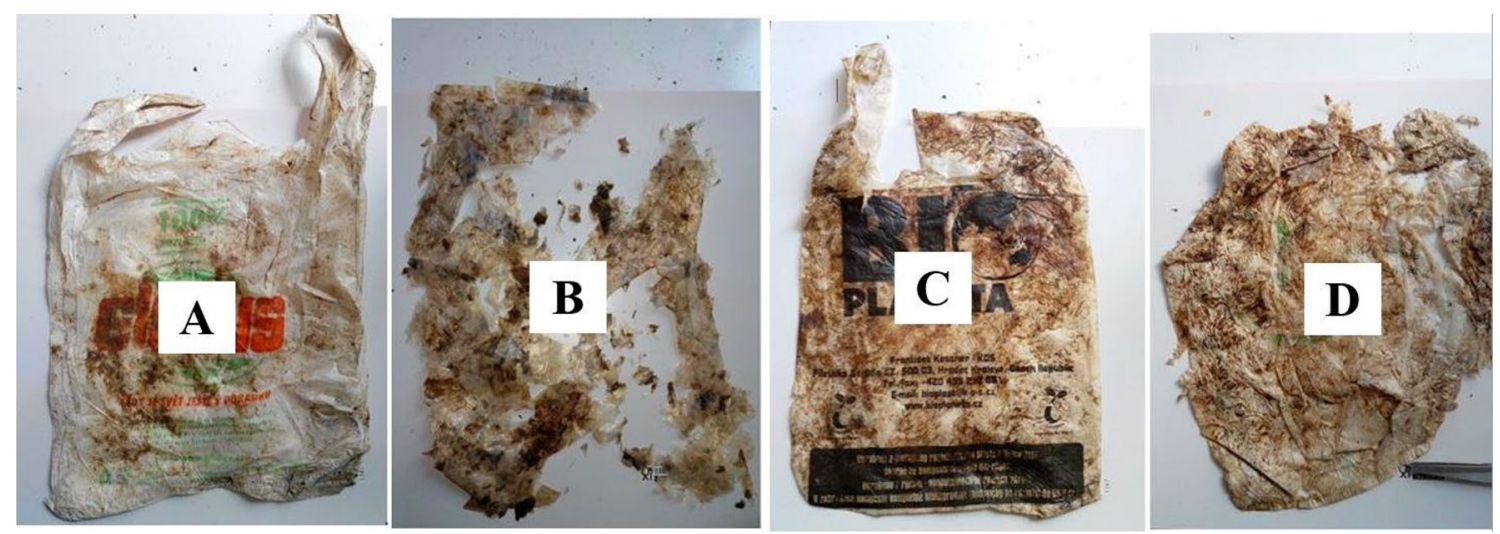

Fig. 7 Photograph of samples after the composting process under real composting conditions was complete 
Acknowledgements This research was financially supported by Grant IGA no. TP 3/2018.

Open Access This article is distributed under the terms of the Creative Commons Attribution 4.0 International License (http://creativeco mmons.org/licenses/by/4.0/), which permits unrestricted use, distribution, and reproduction in any medium, provided you give appropriate credit to the original author(s) and the source, provide a link to the Creative Commons license, and indicate if changes were made.

\section{References}

1. Emadian SM, Onay T, Demirel B (2017) Biodegradation of bioplastics in natural environments. Waste Manage 59:526-536. https ://doi.org/10.1016/j.wasman.2016.10.006

2. Morro A, Catalina F, Sanchez-León E, Abrusci CJ (2018) Polym Environ https://doi.org/10.1007/s10924-018-1350-0

3. Gómez EF, Michel FC (2013) Biodegradability of conventional and bio-based plastics and natural fiber composites during composting, anaerobic digestion and long-term soil incubation. Poly Degrade Stab 98(12):2583-2591. https://doi.org/10.1016/j.polym degradstab.2013.09.018

4. Hammer J, Kraak MHS, Parsons JR (2012) Plastics in the marine environment: the dark side of a modern gift. Rev Environ Contam Toxicol 220:1-44. https://doi.org/10.1007/978-1-4614-3414-6_1

5. Reddy MM, Vivekanandhan S, Misra M, Bhatia SK, Mohanty AK (2013) Biobased plastics and bionanocomposites: current status and future opportunities. Prog Polym Sci 38:1653-1689. https:// doi.org/10.1016/j.progpolymsci.2013.05.006

6. Ishikagi T, Sugano W, Nakanishi A, Tateda M, Ike M, Fujita M, Ishigaki $\mathrm{T}$ (2004) The degradability of biodegradable plastics in aerobic and anaerobic waste landfill model reactors. Chemosphere 54:225-233. https://doi.org/10.1016/S0045-6535(03)00750-1

7. Gupta AP, Dev A, Kumar V (2012) Studies of novel chain linked biodegradable polymers. J Polym Environ 20:514. https://doi. org/10.1007/s10924-011-0402-5

8. Sen C, Das M (2018) Biodegradability of starch based selfsupporting antimicrobial film and its effect on soil quality. $\mathrm{J}$ Polym Environ 26:4331-4337. https://doi.org/10.1007/s1092 4-018-1304-6

9. Mekonnen T, Mussone P, Khalil H, Bressler D (2013) Progress in bio-based plastics and plasticizing modifications. J Mater Chem A 1(43):13379-13398. https://doi.org/10.1039/C3TA12555F

10. Laycock B, Nikolić M, Colwell JM, Gauthier E, Halley P, Bottle S, George G (2017) Lifetime prediction of biodegradable polymers. Prog Poly Sci 71:144-189. https://doi.org/10.1016/j.progp olymsci.2017.02.004

11. Brockhaus S, Petersen M, Kersten W (2016) A crossroads for bioplastics: exploring product developers' challenges to move beyond petroleum-based plastics. J Clean Prod 127:84-95. https ://doi.org/10.1016/j.jclepro.2016.04.003

12. Álvarez-Chávez CR, Edwards S, Moure-Eraso R, Geiser K (2012) Sustainability of bio-based plastics - general comparative analysis and recommendations for improvement. J Clean Prod 23:47-56. https://doi.org/10.1016/j.jclepro.2011.10.003

13. Karana E (2012) Characterization of "natural" and "high-quality" materials to improve perception of bio-plastics. J Clean Prod 37:316-325. https://doi.org/10.1016/j.jclepro.2012.07.034
14. Palsikowski PA, Roberto MM, Sommaggio LRD, Souza PMS, Morales AR (2018) Ecotoxicity evaluation of the biodegradable polymers PLA, PBAT and its blends using allium cepa as test organism. J Polym Environ 26:938. https://doi.org/10.1007/s1092 4-017-0990-9

15. Papong S, Malakul P, Trungkavashirakun R, Wenunun P, Chom-In T. Nithitanakul M, Sarobol E (2014) Comparative assessment of the environmental profile of PLA and PET drinking water bottles from a life cycle perspective. J Clean Prod 65:539-550. https:// doi.org/10.1016/j.jclepro.2013.09.030

16. O'Connor MC (2011) The bioplastics burden. Waste Age 42:44-49

17. Rosato D (2012) Ever evolving bioplastics landscape - bioplastics redefined. Pop Plast Packag 57:40-46

18. Adamcová D, Vaverková MD (2014) Biodegradation of degradable/biodegradable plastic material in controlled composting environment. Pol J Environ Stud 23(5):1465-1474

19. Briassoulis D, Dejean C (2010) Critical review of norms and standards for biodegradable agricultural plastics part I. Biodegradation in soil. J Polym Environ 18:384-400. https://doi. org/10.1007/s10924-010-0168-1

20. Briassoulis D, Dejean C, Picuno P (2010) Critical review of norms and standards for biodegradable agricultural plastics part II: composting. J Polym Environ 18:364-383. https://doi.org/10.1007/ s10924-010-0222-z

21. Vaverková MD, Toman F, Adamcová D, Kotovicová J (2012) Study of the biodegradability of degradable/biodegradable plastic material in a controlled composting environment. Ecol Chem Eng S 19(3):347-358

22. Adamcová D, Vaverková MD, Mašíček T, Břoušková E (2016) Analysis of biodegrability of degradable/biodegradable plastic material in controlled composting environment. J Eco Eng 17(4): $1-10$

23. Vaverková MD, Zloch J, Radziemska M, Adamcová D (2017) Environmental impact of landfill on soils-The example of the Czech Republic. Pol J Soil Sci 50(3):93-105

24. Zloch J, Vaverková MD, Adamcová D, Radziemska M, Vyhnánek T, Trojan V, Đorđević B, Brtnický M (2018) Seasonal changes and toxic potency of landfill leachate for white mustard (Sinapis alba L.). Acta Univ Agric Silvic Mendelianae Brun 66:235-242. https ://doi.org/10.11118/actaun201866010235

25. Gerencsér G, Murányi E, Szendi K, Varga C (2010) Ecotoxicological studies on hungarian peloids (Medicinal Muds). Appl Clay Sci 50(1):47-50. https://doi.org/10.1016/j.clay.2010.06.022

26. OECD Guideline 208 for the Testing of Chemicals (2003) Seedling emergence and seedling growth test

27. Ozkara A, Akyil D, Erdogmus SF, Konuk M (2011) Evaluation of germination, root growth and cytological effects of wastewater of sugar factory (Afyonkarahisar) using Hordeum vulgare bioassays. Environ Monit Assess 183:517-524

Publisher's Note Springer Nature remains neutral with regard to jurisdictional claims in published maps and institutional affiliations. 